\title{
Are we ready for caries prevention through bacteriotherapy?
}

\section{Svante Twetman}

Department of Odontology, Section for Cariology, Endodontics, Pediatric Dentistry and Clinical Genetics, Faculty of Health and Medical Sciences, University of Copenhagen, Copenhagen, Denmark.
* Paper presented at the "Oral Health Under an Integrality Perspective" International Symposium, held at the $17^{\text {th }}$ Congress of the Brazilian Association for Oral Health Promotion (ABOPREV), May 31 to June 2, 2012, Salvador, BA, Brazil.

Declaration of Interests: The author certifies that he has no commercial or associative interest that represents a conflict of interest in connection with the manuscript.

\section{Corresponding Author:}

Svante Twetman

E-mail: stwe@sund.ku.dk

Submitted: Jul 03, 2012

Accepted for publication: Sep 04, 2012

Last revision: Oct 19, 2012
Abstract: Recent insights in medical science indicate that human biofilms play an important role in health and well-being, and have put microbiota modulation through bacteriotherapy into focus. In dentistry, bacterial interference with probiotic bacteria to support the stability and diversity of oral biofilms has gained similar interest. Investigations in vitro into metabolic activity, co-aggregation, growth inhibition, bacteriocin production, and adhesion have collectively suggested a potential role for probiotic lactobacilli and bifidobacteria to modulate the oral microbial ecology. Likewise, short-term clinical studies with intermediate microbial endpoints indicate that interference with caries-associated bacteria seems possible through probiotic dairy products, tablets, lozenges and chewing gum in various dose regimens. Few randomized controlled clinical trials with caries outcomes are available, but three studies with preschool children and the elderly have demonstrated preventive fractions between $21 \%$ and $75 \%$, following regular intake of milk supplemented with probiotic lactobacilli. However, further large-scale trials with orally derived anti-caries candidates are needed before we can say that we are ready for bacteriotherapy as an adjunct to complement the existing evidence-based methods for preventing and controlling caries in daily practice.

Descriptors: Bacteria; Biofilms; Dental Caries; Probiotics.

\section{Introduction}

The interest in bacteriotherapy to prevent and control medical and oral conditions has grown remarkably in recent years. The Human Microbiome Project has provided insights that the biofilms inside and outside our bodies have co-evolved with mankind, and play an important role in maintaining health. This is also true of the oral cavity in which the microbiota does not play a passive role but actively contributes to maintaining oral health. ${ }^{1}$ In other words, the balance between beneficial and pathogenic bacteria is essential for stability and well-being. However, certain ecological shifts in the microbiome allow pathogens to manifest themselves and cause disease. Regarding caries, a frequent consumption of fermentable carbohydrates can lead to an environment that favors aciduric species (e.g. mutans streptococci and lactobacilli), reducing the biofilm diversity and resulting in enamel demineralization. Bacteriotheraphy is the term used when a harmless effector strain is implanted in the host's microflora to maintain or restore a natural microbiome by interference and/or inhibition of other microorganisms, especially patho- 
gens. This could lead to alternative ways of fighting infectious diseases with less harmful side effects, and may also help in the treatment of disorders that seem to have nothing to do with bacteria, such as asthma, obesity and diabetes. Probiotic bacteria, defined as "live microorganisms which, when administered in adequate amounts, confer a health benefit on the host" (WHO), are commonly suggested candidates for bacteriotherapy. Whether or not such bacterial interference applies to dental caries is still an open question. Clinical evaluations of probiotic bacteria that are naturally specific to the mouth are uncommon. So far, strains isolated and developed mostly for gastrointestinal health have been adopted to conduct dental research. These strains could be suboptimal, considering the unique ecological environment that exists in the oral biofilm. The aim of this conference paper was to summarize the current literature on the use of probiotic bacteria as a potential anti-caries measure. For a more comprehensive review, readers may refer to De Vrese and Schrezenmeir. $^{2}$

\section{Mechanisms of action}

Probiotics means "for life" and, in principle, either naturally occurring or genetically engineered strains are used for intervention. The most common probiotic bacteria belong to the lactobacilli and bifidobacteria genera, but certain strains of streptococci have also been investigated. ${ }^{3}$ Lactobacilli are highly acidogenic and aciduric, and grow optimally under slightly acidic conditions. They are considered a part of the normal oral flora and comprise about $1 \%$ of the cultivable species. Bifidobacteria, on the other hand, occur in only minute amounts in the normal oral biofilm. It is important to stress, however, that not all lactic acid bacteria (or bifidobacteria) are probiotic and possess the ability to confer health benefits for the host.

Although the theory that certain bacteria may have beneficial effects on health was presented in early 1900 by Nobel Prize laureate Ilya Metchnikof, the mechanisms of action are still not fully understood. It seems clear, however, that there are local (direct) as well as systemic (indirect) events that occur by regulation of the immune response. Accord- ing to Reid, ${ }^{4}$ the potential avenues are

- (i) co-aggregation and growth inhibition,

- (ii) bacteriocin and hydrogen peroxide production,

- (iii) competitive exclusion through antagonistic activities on adhesion and nutrition, and,

- (iv) immunomodulation.

Consequently, the composition and metabolic activity of the oral biofilm may be temporarily modified. The effects of probiotic bacteria seem strain-specific, and cannot be applied directly to other strains. Moreover, the same strains may have a different effect on different individuals. ${ }^{5}$ Probiotic bacteria do not colonize the host permanently, but permanent colonization is not required for probiotic action to occur. Studies in feces, plaque and saliva clearly show that ingested probiotic bacteria are recovered only up to one week after termination of an intake. $^{6,7}$

\section{Laboratory and animal studies}

Several experimental studies have recently been performed with the main purpose of investigating various biochemical properties of probiotic bacteria and their interaction with oral bacteria in planktonic cultures or in biofilm models. For example, studies on metabolic activity, ${ }^{8}$ co-aggregation, ${ }^{9}$ growth inhibition, ${ }^{10}$ bacteriocin production, ${ }^{3}$ binding to oral structures, saliva and biofilm formation, ${ }^{11}$ have collectively suggested a potential role for probiotic bacteria in modulating the oral microbial ecology. Consequently, the search has started for optimal candidates for the major oral diseases. Nonetheless, the proposed strains have not yet been tested in human clinical trials. ${ }^{12,13}$ One selected candidate, however, has been evaluated in an animal model. Pathogen-free rats were inoculated with $S$. mutans and fed with a cariogenic diet supplemented with a heatkilled probiotic strain (L. paracasei DSMZ16671) or placebo. ${ }^{14}$ The animals were sacrificed after 42 days and a significant caries reduction (preventive fraction of $27 \%$ ) was displayed in the test group compared with the controls. The authors concluded that the intervention appeared efficacious and safe. ${ }^{14}$ 


\section{Clinical trials with microbial endpoints}

There are several short-term studies describing human interventions with probiotic bacteria with caries-related microbiological endpoints in saliva or plaque, as shown in Table $1 .^{15-30}$ All used parallel arms with intervention versus placebo/control, or a crossover design. The sample sizes were generally small and the interventions were shorter than 1 month. A variety of vehicles for the delivery of the live bacteria were used, such as dairy products, ice cream, tablets and lozenges, and the daily dose ranged between $10^{7}$ and $10^{9}$ bacteria. With few exceptions, conventional cultivation on selective agar plates or simple chairside methods were employed; DNA-based methods were reported in only three papers. ${ }^{24,25,28}$ Statistically significant reductions of mutans streptococci in saliva or plaque were reported in two thirds of all studies. However, it was not possible to quantify the magnitude of bacterial decrease, due to the frequent use of categorical scores from chairside bacterial tests rather than bacterial counts. The follow-up samplings were generally conducted at the termination of probiotic intervention, and any information on the post-intervention re-growth of the suppressed target bacteria afterwards was minimal. Interestingly, only three papers found an increase of lactobacilli after the daily intake of probiotic lactobacilli, ${ }^{17,25,28}$ and no study showed a simultaneous reduction of mutans streptococci and increase of lactobacilli. Another observation was that the vehicle or mode of delivery was of minor importance. Matching results were obtained with dairy products such as milk, yogurt, cheese and ice cream, as well as with conventional preparations like tablets, lozenges, powder and drops. Likewise, similar effects on mutans streptococci were obtained with probiotics derived from lactobacilli and bifidobacteria, using various doses. Studies with single strain probiotics have predominated in the literature and there has been insufficient information on multistrain interventions. No negative side effects following the probiotic interventions have been reported.

Table 1 - Short-term clinical trials with microbial endpoints.

\begin{tabular}{|c|c|c|c|c|c|c|}
\hline First author, yr & design $^{a}$ & $\mathrm{n}$; age $(\mathrm{yr})$ & vehicle & time ${ }^{b}$ & strain & major outcome ${ }^{c}$ \\
\hline Ahola, $2002^{15}$ & RCT & $74 ; 18-35$ & cheese & $3 w$ & Lactobac. mix & MS】 \\
\hline Nikawa, $2004^{16}$ & crossover & $40 ; 20$ & milk & $2 w$ & L. reuteri & MS】 \\
\hline Montalto, $2004^{17}$ & RCT & $35 ; 23-37$ & liquid/caps & $45 d$ & Lactobac. mix & $\mathrm{MS} \rightarrow, \mathrm{LB} \nearrow$ \\
\hline Caglar, $2005^{18}$ & crossover & $21 ; 21-24$ & yogurt & $2 w$ & Bifidobacteria & MS】 \\
\hline Caglar, $2006^{19}$ & $\mathrm{RCT}$ & $120 ; 21-25$ & tablet & $2 w$ & L. reuteri & MS】 \\
\hline Caglar, $2007^{20}$ & RCT & $80 ; 21-24$ & gum & $3 w$ & L. reuteri (2 strains) ${ }^{d}$ & MS】 \\
\hline Caglar, $2008^{21}$ & crossover & $40 ; 20-24$ & ice cream & $10 d$ & Bifidobacteria & MS】 \\
\hline Caglar, $2008^{22}$ & RCT & $20 ; 20$ & lozenge & $10 d$ & L. reuteri (2 strains) ${ }^{d}$ & MS】 \\
\hline Cildir, $2009^{23}$ & crossover & $24 ; 12-16$ & yogurt & $2 w$ & Bifidobacteria & MS】 \\
\hline Lexner, $2010^{24}$ & RCT & $20 ; 12-15$ & milk & $2 w$ & L. rhamnosus LB2 1 & $M S \rightarrow$ \\
\hline Sinkiewicz, $2010^{25}$ & RCT & $23 ; 18+$ & diet & $12 w$ & L. reuteri $(2 \text { strains })^{d}$ & $\mathrm{LB} \pi, \mathrm{PI \searrow}$ \\
\hline Singh, $2011^{26}$ & crossover & $40 ; 12-14$ & ice cream & $10 d$ & Bifido. / L. acidophilus & MS】 \\
\hline Jindal, $2011^{27}$ & RCT & $150 ; 7-14$ & powder & $14 d$ & L. rhamnosus / Bifido. & MS】 \\
\hline Marttinen, $2012^{28}$ & crossover & $13 ; 20-30$ & tablet & $2 w$ & L. rhamnosus / reuteri & $M S \rightarrow, L B \nearrow$ \\
\hline Chuang, $2011^{29}$ & $\mathrm{RCT}$ & $78 ; 20-26$ & tablet & $2 w$ & L. paracasei GMNL-33 & $M S, L B \rightarrow$ \\
\hline Cildir, $2012^{30}$ & $\mathrm{RCT}$ & $19 ; \quad 4-12$ & drops & $25 d$ & L. reuteri (2 strains) ${ }^{d}$ & MS, LB $\rightarrow$ \\
\hline
\end{tabular}

${ }^{\circ} \mathrm{RCT}=$ randomized controlled trial, crossover $=$ randomized crossover trial; ${ }^{b} \mathrm{~d}=$ days, $\mathrm{w}=$ weeks; ${ }^{\mathrm{c}} \mathrm{MS} \downarrow=$ significant decrease in salivary mutans streptococci counts, LB $\nearrow$ = significant increase in salivary lactobacilli counts, PI\ = significant decrease in plaque index, $\rightarrow=$ unchanged salivary counts; ${ }^{\mathrm{d}} \mathrm{L}$. reuteri ATCC 55730 and ATCC PTA 5289. 


\section{Clinical trials with caries endpoint}

Until now, three randomized controlled trials (RCT) using milk supplemented with L. rhamnosus (LB21 or GG), with caries as an endpoint, have been published (Table 2)..$^{31-33}$ The first of these studies investigated the effects of probiotic bacteria given to 594 preschool children aged 1-6 years, and showed a significant reduction in caries increment in the probiotic milk group after 7 months, compared to the control group, but only in the subgroup of the 3-4 year-olds. ${ }^{31}$ It was claimed that the 5-day-aweek intake of probiotic milk reduced the risk of caries significantly $(\mathrm{OR}=0.56)$. The second study was a cluster-randomized trial by Stecksén-Blicks et al. ${ }^{32}$ that lasted over 21 months. The results suggested a dramatic reduction in early childhood caries after daily consumption of milk supplemented with L. rhamnosus and $2.5 \mathrm{ppm}$ fluoride, but the effect of the two supplements could not be individualized. In the most recent study on root caries in 160 older adults, ${ }^{33}$ the two factors, fluoride and probiotic bacteria, were separated into two groups, and then combined in a third group. Compared with the control group, all intervention groups showed statistically significant reversals of existing root caries lesions. The combination of fluoride and probiotic bacteria seemed more effective than the probiotic supplement or fluoride alone. ${ }^{33}$ Notably, no statistically significant reductions in the levels of $S$. mutans or lactobacilli were seen in any of the three clinical studies, yet all three showed an obvious effect on caries.

\section{Discussion}

Almost all publications concerning probiotic therapy and oral health were published in the current decade, and there is an obvious risk of publication bias and overrepresentation of positive findings. There is, however, good evidence of probiotic-induced beneficial effects on the gut microbiota and gastro-intestinal health. Insofar as recent studies suggest that there are strong functional similarities between the gut and oral biofilms, it is reasonable to speculate that corresponding health-promoting events may occur in the oral cavity. The observations made in the two major caries trials in children were therefore interesting. ${ }^{31,32}$ Both studies found improvements in general health, along with reductions in caries risk and caries incidence, but the most important findings were probably those related to the use of less prescribed antibiotics. ${ }^{32,34}$ In fact, the findings may support a "metabolic domino effect" in which probiotic therapy is a link between oral and general health; the oral cavity influences and is influenced by general health. Future research will reveal if orally derived probiotic candidates optimized for oral diseases may have a similar dual impact.

A pertinent issue is that the mechanisms of probiotic action are not fully understood. It is generally thought that there are combined local and systemic effects involving adhesion, co-aggregation, competitive inhibition, production of organic acids and bacteriocin-like compounds, and immune-modulation. ${ }^{2,3}$ Although these events have been convincingly demonstrated in the laboratory environment, studies of complex biofilm models or in vivo are still scarce. Moreover, the Human Microbiome Project showed that 75 to 100 species of bacteria predominate in each person's mouth, but different people

Table 2 - Controlled clinical trials with caries as endpoint. Caries development compared with standard milk without supplements.

\begin{tabular}{|c|c|c|c|c|c|c|c|}
\hline First author, yr & design $^{a}$ & $\mathrm{n}$; age (yr) & vehicle, time ${ }^{b}$ & drop-out & strain & caries test/control & $\mathrm{PF}^{c}$ \\
\hline Näse, $2001^{31}$ & $\mathrm{RCT}$ & $\begin{array}{ll}594 ; & 1-6 \\
164 ; & 3-4\end{array}$ & $\begin{array}{l}\text { milk, } 7 \mathrm{~m} \\
\text { milk, } 7 \mathrm{~m}\end{array}$ & $\begin{array}{c}24 \% \\
-\end{array}$ & $\begin{array}{l}\text { L. rhamnosus GG } \\
\text { L. rhamnosus GG }\end{array}$ & $\begin{array}{l}15 \% / 19 \% \\
10 \% / 23 \%\end{array}$ & $\begin{array}{l}21 \% \\
56 \%\end{array}$ \\
\hline Stecksén-Blicks, $2009^{32}$ & CRCT & $174 ; 1-5$ & milk, $21 \mathrm{~m}$ & $25 \%$ & L. rhamnosus LB21 +2.5 ppm F & $\Delta \mathrm{dmfs} 0.4 / 1.6^{\mathrm{d}}$ & $75 \%$ \\
\hline Petersson, $2011^{33}$ & RCT & $160 ; 58-84$ & milk, 15 m & $38 \%$ & L. rhamnosus LB21 & rev $54 \% / 24 \%{ }^{e}$ & $55 \%$ \\
\hline
\end{tabular}

${ }^{\mathrm{a} C C T}=$ randomized controlled trial, $\mathrm{CRCT}=$ cluster randomized controlled trial; ${ }^{\mathrm{b}} \mathrm{m}=$ months; ${ }^{\mathrm{c} P F}=$ prevented fraction; ${ }^{\mathrm{d}} \mathrm{caries}$ prevalence, $\%$; ${ }^{\mathrm{e}} \mathrm{root}$ caries reversals, \%. 
have different combinations of species, insofar as it was found that some of the species prevailing in one person's mouth were rare in another's mouth. Thus, it seems that there is no "one-size-fits-all" which might call for exposure to a mix of beneficial strains rather than to one single strain. The optimal dose for dental diseases is yet to be explored. Up to now, the adopted dose regimens have been based on gastro-intestinal and pediatric health dosing standards. Genetically engineered strains with targeted properties are also expected to appear, ${ }^{35}$ albeit emotional barriers for introducing such strains, especially in children, have already been reported.

The fact that probiotic supplements require regular daily intakes (or at least 4-5 days per week) may be a challenge in terms of patient compliance and costs. The use of dairy products as vehicle for probiotic delivery is desirable from a cariological point of view. Non-sweetened milk, cheese and yogurt have high natural contents of calcium and phosphate that readily decrease the "critical $\mathrm{pH}$ " for enamel dissolution and enhance remineralization. Dietary supplements with probiotic bacteria are also a more economical alternative for the average consumer than tablets or capsules. Nevertheless, commercial interests come before science; there are already a number of probiotic oral health products available for the informed consumer, such as tablets, rinses and toothpastes, but with very limited clinical documentation, if any.

As found in the short-term trials, it seems likely that probiotic lactobacilli and bifidobacteria may exert an antagonistic effect on mutans streptococci in existing biofilms. The current understanding is that enamel demineralization is a result of a carbohydrate-induced shift in the biofilm to aciduric phenotypes. Accordingly, the use of a single group of bacteria as a biomarker for caries development is only partly relevant. A short-term reduction in salivary mutans streptococci may not necessarily be associated with either less caries or reduced caries risk. Attempts have been made to combine professional tooth cleaning and use of antibacterial agents preceding the bacterial interference, in or- der to amplify the effect and or delay re-growth of pathogens. ${ }^{3}$ However, in a recent multicenter study, we failed to demonstrate a lactobacilli-induced effect on re-growth of salivary mutans streptococci after a full-mouth disinfection with chlorhexidine in healthy adults. ${ }^{36}$ On the other hand, the long-term study on root caries indicated that the probiotic supplement worked well when combined with fluoride, ${ }^{31}$ and it seems reasonable to consider the use of bacteriotherapy as one possible adjunct to complement the existing evidence-based methods to prevent and control caries.

The use of probiotics is generally considered safe, although some probiotic strains have been isolated from infections such as endocarditis. ${ }^{37}$ No adverse effects to oral health have been reported so far in clinical trials. Most recent trials were unable to demonstrate increased counts of lactobacilli after the daily intake of probiotic bacteria. Acid production from probiotic lactobacilli could theoretically lead to increased caries risk, but clinical investigations of biofilm acidogenicity have not indicated that this would be the case. ${ }^{27}$ However, long-term studies are needed to firmly establish that the intake of probiotic supplements are more beneficial than harmful. Studies on selected individuals with an ecologically stressed biofilm and proven caries activity would also be helpful to fill the gaps of knowledge.

\section{Conclusions}

Bacterial interference with probiotic bacteria to support the stability and diversity of oral biofilms is gaining momentum in dentistry. Investigations in vitro, as well as clinical studies with bacterial endpoints, suggest that probiotic interference with the oral biofilm seems possible. Only a few randomized, controlled clinical trials reporting caries outcomes are available, but the connection to general health and the obvious caries preventive fractions are promising. However, further large-scale trials with orally derived anti-caries candidates are needed before we can say that we are ready to adopt bacteriotherapy for preventing and controlling caries in clinical practice. 


\section{References}

1. Devine DA, Marsh PD. Prospects for the development of probiotics and prebiotics for oral applications. J Oral Microbiol. 2009 May 1;1. doi: 10.3402/jom.v1i0.1949.

2. de Vrese M, Schrezenmeir J. Probiotics, prebiotics, and synbiotics. Adv Biochem Eng Biotechnol. 2008;111:1-66.

3. Teughels W, Van Essche M, Sliepen I, Quirynen M. Probiotics and oral healthcare. Periodontol 2000. 2008 Oct;48(1):11147.

4. Reid G, Younes JA, Van der Mei HC, Gloor GB, Knight R, Busscher HJ. Microbiota restoration: natural and supplemented recovery of human microbial communities. Nat Rev Microbiol. 2011 Jan;9(1):27-38.

5. Kõll-Klais P, Mandar R, Leibur E, Marcotte H, Hammarström $\mathrm{L}$, Mikelsaar M. Oral lactobacilli in chronic periodontitis and periodontal health: species composition and antimicrobial activity. Oral Microbiol Immunol. 2005 Dec;20(6):354-61.

6. Yli-Knuuttila H, Snäll J, Kari K, Meurman JH. Colonization of Lactobacillus rhamnosus GG in the oral cavity. Oral Microbiol Immunol. 2006 Apr;21(2):129-31.

7. Ravn I, Dige I, Meyer RL, Nyvad B. Colonization of the oral cavity by probiotic bacteria. Caries Res. 2012;46(2):107-12 .

8. Hedberg M, Hasslöf P, Sjöström I, Twetman S, Stecksén-Blicks C. Sugar fermentation in probiotic bacteria - an in vitro study. Oral Microbiol Immunol. 2008 Dec;23(6):482-5.

9. Twetman L, Larsen U, Fiehn NE, Stecksén-Blicks C, Twetman S. Coaggregation between probiotic bacteria and cariesassociated strains: An in vitro study. Acta Odontol Scand. 2009;67(5):284-8.

10. Keller MK, Hasslöf P, Stecksén-Blicks C, Twetman S. Coaggregation and growth inhibition of probiotic lactobacilli and clinical isolates of mutans streptococci: an in vitro study. Acta Odontol Scand. 2011 Sep;69(5):263-8.

11. Söderling EM, Marttinen AM, Haukioja AL. Probiotic lactobacilli interfere with Streptococcus mutans biofilm formation in vitro. Curr Microbiol. 2011 Feb;62(2):618-22.

12. Bosch M, Nart J, Audivert S, Bonachera MA, Alemany AS, Fuentes MC, et al. Isolation and characterization of probiotic strains for improving oral health. Arch Oral Biol. 2012 May;57(5):539-49.

13. Samot J, Lebreton J, Badet C. Adherence capacities of oral lactobacilli for potential probiotic purposes. Anaerobe. 2011 Apr;17(2):69-72.

14. Tanzer JM, Thompson A, Lang C, Cooper B, Hareng L, Gamer A, et al. Caries inhibition by and safety of Lactobacillus paracasei DSMZ16671. J Dent Res. 2010 Sep;89(9):921-6.

15. Ahola AJ, Yli-Knuuttila H, Suomalainen T, Poussa T, Ahlstrom A, Meurman JH, et al. Short-term consumption of probiotic-containing cheese and its effect on dental caries risk factors. Arch Oral Biol. 2002 Nov;47(11):799-804.

16. Nikawa H, Makihira S, Fukushima H, Nishimura H, Ozaki Y, Ishida K. Lactobacillus reuteri in bovine milk fermented decreases the oral carriage of mutans streptococci. Int J Food Microbiol. 2004 Sep 1;95(2):219-23.

17. Montalto M, Vastola M, Marigo L, Covino M, Graziosetto $\mathrm{R}$, Curigliano V, et al. Probiotic treatment increases salivary counts of lactobacilli: a double-blind, randomized, controlled study. Digestion. 2004;69(1):53-6.

18. Caglar E, Sandalli N, Twetman S, Kavaloglu S, Ergeneli S, Selvi S. Effect of yogurt with Bifidobacterium DN-173 010 on salivary mutans streptococci and lactobacilli in young adults. Acta Odontol Scand. 2005 Nov;63(6):317-20.

19. Caglar E, Cildir SK, Ergeneli S, Sandalli N, Twetman S. Salivary mutans streptococci and lactobacilli levels after ingestion of the probiotic bacterium Lactobacillus reuteri ATCC 55730 by straws or tablets. Acta Odontol Scand. 2006 Oct;64(5):314-8.

20. Caglar E, Kavaloglu SC, Kuscu OO, Sandalli N, Holgerson PL, Twetman S. Effect of chewing gums containing xylitol or probiotic bacteria on salivary mutans streptococci and lactobacilli. Clin Oral Investig. 2007 Dec;11(4):425-9.

21. Caglar E, Kuscu OO, Selvi Kuvvetli S, Kavaloglu Cildir S, Sandalli N, Twetman S. Short-term effect of ice-cream containing Bifidobacterium lactis Bb-12 on the number of salivary mutans streptococci and lactobacilli. Acta Odontol Scand. 2008 Jun;66(3):154-8.

22. Caglar E, Kuscu OO, Cildir SK, Kuvvetli SS, Sandalli N. A probiotic lozenge administered medical device and its effects on salivary mutans streptococci and lactobacilli. Int J Paediatr Dent. 2008 Jan;18(1):35-9.

23. Cildir SK, Germec D, Sandalli N, Ozdemir FI, Arun T, Twetman $S$, et al. Reduction of salivary mutans streptococci in orthodontic patients during daily consumption of yoghurt containing probiotic bacteria. Eur J Orthod. 2009 Aug;31(4):40711.

24. Lexner MO, Blomqvist S, Dahlén G, Twetman S. Microbiological profiles in saliva and supragingival plaque from cariesactive adolescents before and after a short-term daily intake of milk supplemented with probiotic bacteria - a pilot study. Oral Health Prev Dent. 2010;8(4):383-8.

25. Sinkiewicz G, Cronholm S, Ljunggren L, Dahlén G, Bratthall G. Influence of dietary supplementation with Lactobacillus reuteri on the oral flora of healthy subjects. Swed Dent J. 2010;34(4):197-206.

26. Singh RP, Damle SG, Chawla A. Salivary mutans streptococci and lactobacilli modulations in young children on consumption of probiotic ice-cream containing Bifidobacterium lactis Bb12 and Lactobacillus acidophilus La5. Acta Odontol Scand. 2011 Nov;69(6):389-94.

27. Jindal G, Pandey RK, Agarwal J, Singh M. A comparative evaluation of probiotics on salivary mutans streptococci counts in Indian children. Eur Arch Paediatr Dent. 2011 Aug;12(4):2115. 
28. Marttinen A, Haukioja A, Karjalainen S, Nylund L, Satokari $\mathrm{R}$, Öhman C, et al. Short-term consumption of probiotic lactobacilli has no effect on acid production of supragingival plaque. Clin Oral Investig. 2012 Jun;16(3):797-803.

29. Chuang L-C, Huang C-S, Ou-Yang L-W, Lin S-Y. Probiotic Lactobacillus paracasei effect on cariogenic bacterial flora. Clin Oral Investig. 2011 Aug;15(4):471-6.

30. Cildir S, Sandalli N, Alp F, Caglar E. A novel delivery system of probiotic drop and its effect on dental caries risk factors in cleft lip/palate children. Cleft Palate Craniofac J. 2012 May;49(3):369-72.

31. Näse L, Hatakka K, Savilahti E, Saxelin M, Pönkä A, Puossa $\mathrm{T}$, et al. Effects of long-term consumption of a probitic bacterium, Lactobacillus rhamnosus GG, in milk on dental caries and caries risk in children. Caries Res. 2001 NovDec;35(6):412-20.

32. Stecksén-Blicks C, Sjöström I, Twetman S. Effect of longterm consumption of milk supplemented with probiotic lactobacilli and fluoride on dental caries and general health in preschool children: a cluster-randomized study. Caries Res. 2009;43(5):374-81.
33. Petersson LG, Magnusson K, Hakestam U, Baigi A, Twetman S. Reversal of primary root caries lesions after daily intake of milk supplemented with fluoride and probiotic lactobacilli in older adults. Acta Odontol Scand. 2011 Nov;69(6):321-7.

34. Hatakka K, Savilahti E, Pönkä A, Meurman J, Poussa T, Näse $\mathrm{L}$, et al. Effects of long term consumption of probiotic milk on infections in children attending day care centres: double blind randomised trial. BMJ. 2001 Jun 2;322(7298):1327-9.

35. Zarco MF, Vess TJ, Ginsburg GS.The oral microbiome in health and disease and the potential impact on personalized dental medicine. Oral Dis. 2012 Mar;18(2):109-20.

36. Keller MK, Hasslöf P, Dahlén G, Stecksén-Blicks C, Twetman S. Probiotic supplements (Lactobacillus reuteri DSM 17938 and ATCC PTA 5289) do not affect regrowth of mutans streptococci after full-mouth disinfection with chlorhexidine: a randomized controlled multicenter trial. Caries Res. 2012;46(2):140-6.

37. Cannon JP, Lee TA, Bolanos JT, Danziger LH. Pathogenic relevance of Lactobacillus: a retrospective review of over 200 cases. Eur J Clin Microbiol Infect Dis. 2005 Jan;24(1):31-40. 